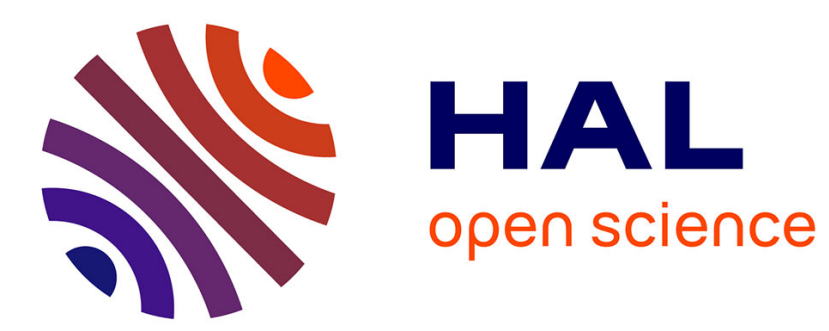

\title{
A reply to Daniel Weinstock and Avigail Eisenberg \\ Patrick Loobuyck
}

\section{To cite this version:}

Patrick Loobuyck. A reply to Daniel Weinstock and Avigail Eisenberg. Ethnicities, 2005, 5 (1), pp.132-135. 10.1177/146879680500500109 . hal-00571826

\section{HAL Id: hal-00571826 \\ https://hal.science/hal-00571826}

Submitted on 1 Mar 2011

HAL is a multi-disciplinary open access archive for the deposit and dissemination of scientific research documents, whether they are published or not. The documents may come from teaching and research institutions in France or abroad, or from public or private research centers.
L'archive ouverte pluridisciplinaire HAL, est destinée au dépôt et à la diffusion de documents scientifiques de niveau recherche, publiés ou non, émanant des établissements d'enseignement et de recherche français ou étrangers, des laboratoires publics ou privés. 


\section{A reply to Daniel Weinstock and Avigail Eisenberg}

\section{PATRICK LOOBUYCK}

Ghent University, Belgium

I am grateful to Daniel Weinstock and Avigail Eisenberg for their comments on my ideas concerning liberal multiculturalism and my concept of 'multicultural measures'. Following their remarks, I would now like to clarify a number of points.

Both Weinstock and Eisenberg have observed that I have given insufficient reason to show that the proposed multicultural measures are only temporary. My text can indeed give rise to misunderstanding in this matter. It is not my intent to deny a place in liberal multiculturalism for permanent measures to accommodate diversity and pluralism.

My case for active pluralism as a form of moderate, pragmatic secularism instead of radical secularism implies various permanent measures in order to guarantee pluralism in the public sphere (versus a politics of laissez-faire or hands-off neutrality). For example, if a liberal policy wishes to guarantee that citizens 'shall not be denied the right to profess and practice their own religion', this will imply some permanent measures. Provision of (permanent) subsidies to the various recognized religions is a possible option. Also, the idea, mentioned by Eisenberg, that all public institutions, rules and practices must be scrutinized to determine whether they are unfairly biased can be seen as a permanent component of a policy that actively strives to implement a just multicultural society.

The difference between these permanent measures and the temporary multicultural measures as defined in my article on liberal multiculturalism, is that the former do not constitute group differentiated measures. They are measures that support multiculturalism, but apply equally to the various groups. For instance, if a government decides to actively support pluralism by subsidizing the various recognized religions, or by offering courses in the various religions as part of the public education system, then the subsidies and educational support must apply with the same criteria to all of the recognized religions. Indeed, if this is not the case, and the various groups are treated differently, this will often be viewed as an injustice. The subsidy system in Belgium contains an injustice in this area since it differentiates between the financial support given to the Catholic church and other religions: while the subsidy given to the Catholic church is based on the number of inhabitants per parish, regardless of their faith, other religions are subsidized on the basis of the number of their membership. This financial system gives an unfair advantage to the Catholic religion. 
Almost no one disputes 'that equality is key amongst the principles that ought to guide public deliberation and decision making in diverse societies', as Eisenberg also observes. In as far as everybody indeed agrees that 'egalitarianism provides the only defensible context in which cultural diversity is appropriately protected', good and valid reasons must be given if a groupdifferentiated policy is to be implemented. As I have argued, this can only occur on condition that the special treatment of certain groups serves to neutralize an unfair inequality of opportunities that all citizens legitimately strive for. Egalitarian liberalism does not rule out group-based policies, but these policies are only legitimate on certain conditions. The group-differentiated multicultural measures as proposed in my paper are thus conditional; they are only legitimate as long as they are necessary to rectify an unfair disadvantage or inequality. This is what I mean by the idea that the group-differentiated multicultural measures are 'in principle' temporary - as long as the unfair inequality persists. Again, this does not rule out the possibility that these measures will in practice have a permanent character, because, for example, there may be no other way to eliminate the inequality. I do not think that the question about permanent or temporary measures is 'entirely contingent', as Weinstock argues, or is 'not an issue at the heart of the debate about multiculturalism', as Eisenberg asserts: various egalitarian opponents of minority rights specifically criticize the idea of minority rights because they imply permanent groupdifferentiated measures to perpetuate cultural differences indefinitely. With my argument, I aim to disarm this criticism, and thereby maintain the validity of several of the multicultural proposals formulated by Kymlicka and others.

In summary, we can differentiate between multicultural measures that are intended to fairly promote pluralism by treating various groups in the same fashion, and measures which are intended to fairly promote pluralism by treating groups in a differentiated fashion. In my article, I have regarded only this last category as multicultural measures: it concerns groupdifferentiated measures for ethnic, cultural and religious minorities. The argument that multicultural measures are temporary, then, concerns only these group differentiated measures, not measures that apply equally to all groups.

Another problem, raised by Weinstock, is about my use of the 'ruleand-exemption' approach. He argues that if it is allowed for schoolchildren to absent themselves from classes for religious reasons, there must be many other good reasons for parents to take their children out of school at odd times. He says, 'What the case of the Flemish directive reveals is that the state ought to give parents this latitude for a whole host of valid reasons, and not solely for specifically cultural or religious ones.' I think this is right, but in fact, it is the other way around: because parents sometimes have good reason to keep their children from school, there is a long-standing 
regulation that permits this. On parental authority, children may legally be absent for a limited number of (half) days. The novelty of the new directive is that religious holy days are now explicitly recognized under certain circumstances as a valid reason for absence.

Should we then not have a regulation that explicitly recognizes a visit to good old Aunt Millie at the retirement home, or a family vacation to the countryside, as valid reasons for absence? I think not. First, the differentiation between choice and circumstance as previously mentioned is relevant here. Furthermore, there are sufficient regular school vacations for such activities. In the case of religious holy days, this is different: membership of a religion is not a free choice, and it is not possible to reschedule holy days to fit school vacations.

Above all, and this is the essence of my argument, it concerns a particular measure intended to create more equality, specifically in the area of religious observance. The proposed multicultural measure has the intention to rectify an unfair inequality. This equality argument has no relevance to parents who take their children from school to visit Aunt Millie.

And as we have seen, use of the 'sufficiency principle' also puts a brake on the slippery slope which Weinstock warns us of. In this area, there is a difference between the traditional liberals such as Barry, for whom access to the culture of choice forms no part in their discussions about justice, and the liberal culturalists such as Carens Raz and Kymlicka for whom access to your own culture is an essential element of justice. Contrary to the suggestion of Eisenberg, Barry does not actually elaborate on the question of an acceptable minimum for cultural experience which should be guaranteed by government, since he regards cultural identity as a personal (and sometimes expensive) preference which is entirely the responsibility of the individual concerned. The sufficiency principle is only relevant for those writers who wish to consider access to the culture of choice as a primary social good. I admit that the sufficiency principle does not give unambiguous guidance, yet 'what counts as the minimally acceptable level of cultural experience' can only allow a limited breadth of interpretation. The various religious communities and their members will usually make clear what is for them the essential minimum, and it is the task of a multicultural policy to determine to what extent this minimum can be provided without violating liberal principles.

In conclusion, a few words about Eisenbergs's remark that liberalism is culturally specific and under-inclusive. In that context, I would point to the difference between liberalism as a historically rooted practice, and liberalism as a normative political theory. It is quite possible that historical liberalism does not live up to theoretical ideals, and might never do so due to the need for practical application within a complex historical and social reality. Philosophical liberalism, however, is based on autonomy as a core value. The concept of tolerance is an essential corollary of this. If it should appear 
that there are elements present in historical liberalism which conflict with the ideals of philosophical liberalism, then historical liberalism should adapt itself to the extent possible. Such discrepancies between historical and philosophical liberalism can occur because liberalism is in practice insufficiently refined and matured, or that new circumstances challenge historical liberalism, or that theories are incorrectly applied, or a combination of the above factors.

Regarding the origins of liberalism, Eisenberg is right: every liberal political system has historical roots and often de facto favours the cultural majority. It is precisely the role of liberal multiculturalism to readjust the day-to-day practice of liberalism where that might result in 'marginalization and disadvantage for people who do not share in the historical traditions and debates that gave rise to and sustain these values'. Eisenberg writes that it is a permanent project of multiculturalism within liberal societies 'to determine, on the basis of a fuller inclusion of ethnically diverse peoples, which liberal values and institutions are inflexible, which are unfairly biased, which can and should be altered and which cannot be altered'. According to Eisenberg, we have to distance ourselves from liberalism in order to expand the possibilities of our own theories about equality and individual well-being. Here, I do not agree. To expand the possibilities of our own theories about equality and individual well-being, we do not have to distance ourselves from liberalism. On the contrary, liberalism can develop and adapt itself from within. Contrary to Eisenberg, I am convinced that criticism of liberal values and institutions as historically evolved and functioning in social practice can be delivered from within liberal political philosophy itself. Liberalism as a set of theoretical ideals about autonomy, pluralism and equality has a great deal of potential to readjust the liberal social reality. That is also what I mean by the sentence: in practice, liberalism does not make full use of its multicultural potential. It is the task of multicultural liberalism to reveal and apply that multicultural potential within liberalism.

PATRICK LOOBUYCK is a moral philosopher at the Department of Philosophy and Moral Sciences, Ghent University. Address: Faculty of Arts and Philosophy, Department of Philosophy and Moral Sciences, Blandijnberg 2, 9000 Ghent, Belgium. [email: Patrick.Loobuyck@UGent.be] 